\title{
Open Source, Open Innovation and Intellectual Property Rights - A Lightning Talk
}

\author{
Terhi Kilamo ${ }^{1}$, Imed Hammouda ${ }^{1}$, Ville Kairamo ${ }^{2}$, \\ Petri Räsänen ${ }^{2}$, and Jukka P. Saarinen ${ }^{3}$ \\ 1 Tampere University of Technology \\ firstname.lastname@tut.fi \\ 2 Uusi Tehdas/New Factory \\ firstname.lastname@hermia.fi \\ 3 Nokia Research Center \\ jukka.p.saarinen@nokia.com
}

\begin{abstract}
Open innovation projects are fast paced aiming at producing a quick proof of concept of an innovative software product. This need for speedy results makes the use of open source components as a basis for the work appealing. Open source brings with it an inherent risk of license conflicts that may become an issue when aiming to develope an innovative demo into an actual product. In this study, the first results of investigating the knowledge the participants of innovation projects have on intellectual property are presented. The effect this may have on the project results is also discussed.
\end{abstract}

\section{Introduction}

Ongoing and fast-paced innovation is becoming a vitality to companies in the software business. Innovation can lie in any commodity; it commonly is a novelty that can be put into actual, practical use. Many companies rely on innovation projects to create better products and to improve their internal processes 2 . Open innovation environments allow businesses to reach beyond the company scope in the search for new concepts, ideas and business opportunities.

Innovation, and open innovation especially, comes with a number of challenges such as motivation, integration and exploitation of the results 13. It needs a governance framework [4] that enables organizational alignment of the different partners, proper handling of intellectual property rights (IPR) issues, and the emergence of new kinds of business opportunities. These challenges have to be taken into account when building any open innovation platform with the goal of driving future development and solutions. One major issue affecting exploitation and emergence of business opportunities is the handling of intellectual property.

A natural requirement for a open innovation environment is a mutually beneficial and agreeable IPR model. In addition, the IPR issues need to be further taken into account in development of innovation projects and when commercializing their results. The focus in this paper is to investigate to what extend do the university student participants of open innovation projects consider IPR issues

I. Hammouda et al. (Eds.): OSS 2012, IFIP AICT 378, pp. 298-303, 2012.

(C) IFIP International Federation for Information Processing 2012 
such as licensing in their development. The paper motivates the problem and gives some preliminary results.

The rest of the paper is structured as follows. Section 2 provides background for and motivates the study. Section 3 explains the research setting and some preliminary results are presented in Section 4. Finally Section 5 discusses the findings and concludes the paper.

\section{Research Motivation}

This section discusses the background for the study including related work. The motivation for the study is given with the research goal and research questions the study aims to answer.

\subsection{Background}

Demola 119 is an open innovation platform intended for academic students. It aims to develop innovative products and demos within multidisciplinary and agile project teams. The project ideas are initiated by local businesses and public organisations and thus have practical business importance. Demola also gives support for emerging business ideas and encourages start-ups based on these projects. A model for managing immaterial rights that supports all this and respects the authors is offered. Demola is now in its third year of operation with several successful projects completed.

The Demola IPR Model. One significant factor in building an innovation environment that is attractive to all of its participants is the management of intellectual property within. The Demola IPR agreement maintains the authors rights to their work giving the project partner company full utilization rights, if they so want, at the same time. Only the project results are under this kind of agreement, prior knowledge is excluded. The agreement entered also states that the project results must not contain third party trade secrets, third party owned parts or otherwise copyrighted material and should be usable without any IPR protected material. Software licenses from the open source perspective are not addressed in the IPR agreement. All immaterial rights are handled the same.

Related Work. With the rise of free/libre/open source software (FLOSS) and FLOSS components utilized in software projects the importance of legality concerns has risen. The focus in research has mainly been to license analysis on the software level to either identify the licenses [8] or to check the code against license compatibilities 512. These methods do not support license awareness at the time of development but focus at final source code instead. Research effort has also been directed to finding ways of documenting the legal rules [710]. Our aim here is on the individual developers and how they regard IPR and licensing in a short and hectic innovative software project. These topics are scarcely taught in standard software engineering degree program curricula which increases the interest to study the current level of knowledge. With works such as [361] it is evident that further legality research is needed. 


\subsection{Research Goals}

The goal of this paper is to investigate to what extent students from different academic levels take intellectual property rights into account when working in quick paced open innovation projects. These projects are run in Demola and the results should be usable by the companies in their further commercial products.

The Demola contract model allows the project partner to purchase rights to the project results. The project perspective is however more on getting the project completed and to show a functional end result or at least a demo level proof of concept. This may direct the project groups to not take IPR issues such as licensing and license compatibility into account while working on the project. Furthermore, as the projects are relatively short framed the likelihood of utilizing open source licensed components is notable. Not having to implement everything from scratch leaves the projects more freedom to focus on the actual innovation in the project.

The research questions are:

Q1 How much prior knowledge the participating students of the Demola innovation projects have in IPR issues?

Q2 Do they utilize open source components in the projects?

Q3 Are the IPR issues characteristic to software and open source taken into consideration?

Q4 Based on the three first questions: does IPR cause inherent risks to the project partners in acquiring rights to the end product?

\section{Research Design}

In order to map out the project groups' attitudes towards IPR issues while working on the project, we conducted a survey targeted towards local technology students, who had completed a Demola project. A survey available online1 was used.

The survey consisted of 14 questions that queried the project participants' background (Q1), usage of open source components in the project (Q2), prior knowledge in IPR issues in software (Q3) and how significant the risk for different software IPR violations is estimated as (Q4).

The survey was sent to students who have completed a Demola project in the past. The initial phase of the research reported in this paper targeted only a small sample group of students who have recently completed or are just completing a Demola project. A wider study of all Demola project participants is planned in the near future based on the experiences collected here.

\section{IPR Knowledge in Projects}

At this trial round of the survey, in total nine people answered the survey. There were in addition nine incomplete answers that are left out of the results presented

\footnotetext{
${ }^{1}$ Survey available at: ossli.cs.tut.fi/survey/index .php?sid=44979
} 
here and one with most of the fields left empty. Each of the respondents came from a different project so in total nine projects are represented. Four of them had had their project licensed by the company behind it and one was still in progress.

Four of the respondents had utilized open source components in their work and described a pattern we had predicted where open source software was used in order to avoid writing large amounts of code. Also open source development tools were mentioned. There were three respondents who answered this with "uncertain" and one left the field unanswered.

Table 1. Knowledge of legality issues

\begin{tabular}{|c|c|c|c|c|c|}
\hline & knowledgeable & quite a lot & a little & none & no answer \\
\hline Patents and licences & 2 & 3 & 2 & 1 & 1 \\
License compatibility & 1 & 1 & 3 & 3 & 1 \\
Specifics of FLOSS & 2 & 1 & 5 & 0 & 1 \\
Copyleft in FLOSS & 1 & 3 & 3 & 1 & 1 \\
\hline
\end{tabular}

Prior knowledge in legality aspect varied but the specifics of open source were less familiar than licences and patents as general concepts. Only one respondent answered to be knowledgeable in the FLOSS licenses' copyleft requirement. Five had only a little knowledge in FLOSS specifics. License compatibility was a little known issue to $67 \%$ of the respondents, The knowledge reported by the respondents is listed in Table 1

The risks were all in all considered significant. The risks evaluated and the answers are listed in Table 2, License terms infringement and third party risks were considered as the highest risks while quite a high risk was also seen in patent infringements in general. Open source related questions saw a rise in unanswered questions. License incompatibility was considered as a risk by two respondents still, while four saw the courtroom as a risk.

Table 2. Risks considered in replies

\begin{tabular}{|c|c|c|c|c|}
\hline Risk & \multicolumn{4}{|c|}{ Seriousness } \\
& Extreme & Moderate & Not relevant & No answer \\
\hline Product infringes on a software patent & 2 & 2 & 3 & 2 \\
\hline $\begin{array}{c}\text { Product contains code that unbeknownst } \\
\text { to you belongs to third party }\end{array}$ & 2 & 4 & 2 & 1 \\
\hline $\begin{array}{c}\text { Product contains code that unbeknownst } \\
\text { to you is covered by third parties trade secret }\end{array}$ & 3 & 2 & 3 & 1 \\
\hline $\begin{array}{c}\text { Product contains code that unbeknownst } \\
\text { to you is violating its license terms }\end{array}$ & 3 & 2 & 2 & 2 \\
\hline $\begin{array}{c}\text { Open source licenses are incompatible } \\
\text { with each other }\end{array}$ & 1 & 1 & 3 & 4 \\
\hline Open source licenses do not stand up in court & 2 & 2 & 2 & 3 \\
\hline Patent law suits & 2 & 1 & 0 & 1 \\
\hline
\end{tabular}




\section{Discussion and Conclusion}

The replies into the initial study were scarce and thus it is difficult to draw any major conclusions based on the results. We can give initial answers to the research questions but no real weight is there yet. However, the results do indicate only a little care is given to IPR issues when working on the project which supports our hypothesis that there is an inherent risk there. Furthermore, we are going to add more data into the final version of the paper.

The result seems to indicate a problem also in regard to the risks themselves. The participants find the most significant risks where there should not be none given the IPR agreement, such as third party code, trade secrets and patents. Open source - while utilized - is not deemed as such a high risk which itself gives a reason to suspect there is one. Furthermore in FLOSS related issues the number of no answers increases which leads to suppose a knowledge gap is there.

Part of the reason why the complete answer percentage was so low may be in the feedback we got from the students that they had not understood some of the questions. While the survey itself can be improved in some respects, this indicates that there may very well be a large gap in the participants' IPR knowledge. Overall the results themselves suggest that the participants don't have a sufficient knowledge in IPR matters and what knowledge there is dwindles significantly in FLOSS related issues.

What the study already shows is that there is a need for a wider survey of open innovation project participants. There seems to be a need for a set of recommendations to the participants to take into account when working on the projects regarding the intellectual property rights issues. Currently, the project participants at least are vary of the product not being sound in IPR. Mapping out what the participants know would help in giving recommendations and supporting the projects also in respect to IPR. This could further enforce the IPR and software legality matters to be mode widely included more into the software engineering curricula.

\section{References}

1. Alspaugh, T.A., Asuncion, H.U., Scacchi, W.: Analyzing software licenses in open architecture software systems. In: Proceedings of the 2009 ICSE Workshop on Emerging Trends in Free/Libre/Open Source Software Research and Development, FLOSS 2009, pp. 54-57. IEEE Computer Society Press (2009)

2. Chesbrough, H.: Open Innovation: Researching a New Paradigm, chapter Open Innovation: A New Paradigm for Understanding Industrial Innovation. Oxford University Press (2006)

3. Di Penta, M., German, D.M., Guéhéneuc, Y., Antoniol, G.: An exploratory study of the evolution of software licensing. In: Proceedings of the 32nd ACM/IEEE International Conference on Software Engineering, ICSE 2010, vol. 1, pp. 145-154. ACM (2010)

4. Feller, J., Finnegan, P., Hayes, J., O'Reilly, P.: Institutionalising information asymmetry: governance structures for open innovation. Information Technology \& People 22(4), 297-316 (2009) 
5. Fossology, http://fossology.org (last visited March 2012)

6. Germán, M., Di Penta, D., Davies: Understanding and auditing the licensing of open source software distributions. In: Proceedings of the 18th International Conference on Program Comprehension, pp. 84-93. IEEE (2010)

7. Hoekstra, R., Breuker, J., Di Bello, M., Boer, A.: The LKIF Core Ontology of Basic Legal Concepts. In: Proceedings of LOAIT, pp. 43-63 (2007)

8. A license code indetification tool for source code, http://ninka.turingmachine.org/ (last visited March 2012)

9. Facilitating Innovation at Demola. Open Threads: Open Innovation Newsletter (April 2009)

10. The Qualipso Project, http://www.qualipso.org/licenses-champion (last visited March 2012)

11. Demola Innovation Platform, http://www.demola.fi (last visited March 2012)

12. Tuunanen, T., Koskinen, J., Kärkkäinen, T.: Automated Software License Analysis. Automated Software Engineering 16(3-4), 455-490 (2009)

13. West, J., Gallagher, S.: Challenges of Open Innovation: The Paradox of Firm Investment in Open-Source Software. R\&D Management 36(3), 319-331 (2006) 